\title{
Arbor
}

\section{El ámbito de lo íntimo}

\section{Pedro Rodríguez Panizo}

Arbor CLXXI, 676 (Abril), 705-718 pp.

El ámbito de lo íntimo tiene que ver, en el mundo de lo religioso, con la experiencia mística. Frente al lado visible y analizable del fenómeno religioso está también su lado interior. El presente artículo, de la mano de algunos textos de san Juan de la Cruz, intenta explorar, a través de las pistas elusivas de un místico sin igual, la estructura del camino místico y la experiencia de radical transformación que supone en la vida de cuantos se atreven a introducirse en esa travesía dramática pero llena de plenitud.

Hablar de lo íntimo en el ámbito de la experiencia religiosa es, sin duda, referirse al fenómeno místico. Si todo dato religioso apunta, por un lado, a la Realidad de la religión (el Misterio), a la que simboliza y, por otra parte, expresa la vida religiosa; en el caso de los místicos aparece significado con mucha mayor fuerza este hecho de poseer el fenómeno un lado visible que expresa una intención que no se agota en él pero que la hace posible como expresión de la vida religiosa y como apuntamiento del Misterio. Por acaecer la experiencia de éste en lo más íntimo del sujeto, y debido al carácter elusivo de la Realidad de la religión en el testimonio del místico, muchas veces expresado paradójicamente por el silencio, se hace difícil acceder a lo «íntimo» de esa experiencia si no fuera por los signos, también «elusivos», que nos dan muchos de ellos con sus textos y su vida (símbolos, poemas, tratados, etc.). La valoración del lenguaje místico, expresado en los innumerables documentos que nos han legado, hace que las peculiares expresiones literarias de la experiencia mística posean una variedad enorme de géneros literarios que van desde las explo- 
siones más doxológicas, pasando por las expresiones simbólicas y poéticas hasta los testimonios autobiográficos o teológicos. Al ser un lenguaje eminentemente experiencial, el místico, aunque sea también un consumado teólogo, privilegia no tanto el hablar de Dios, cuanto el hablar propio del que se le ha agraciado con una presencia originaria concreta ( $P a$ tiens divina). De ahí el carácter paradójico de esta experiencia y su índole escondida y secreta como una noche oscura o «mística teología, que quiere decir sabiduría de Dios secreta o escondida, en la cual, sin ruido de palabras y sin ayuda de algún sentido corporal ni espiritual, como en silencio y quietud, a oscuras de todo lo sensitivo y natural, enseña Dios ocultísima y secretísimamente al alma sin ella saber cómo; lo cual algunos espirituales llaman entender no entendiendo» (SAN JUAN DE LA CRUZ, Cántico espiritual [B], 39, 12).

Lo místico se caracteriza, entonces, por un fuerte subrayado de lo experiencial, de esa especial intensidad que tiene en ellos la vivencia de su propia religión, la «presencia en la experiencia» o experiencia «sensible», fruitiva, de encuentro con el Misterio configurado de las más variadas formas; es decir, no sólo sabido, no algo de lo que se habla sin más, sino una realidad padecida. El místico tiene conciencia de esa Presencia constituyente que se le está dando, haciendo posible su constitución como sujeto al sentirse término de esa donación o agraciamiento originarios. La conciencia de la unidad o unión, dependiendo del carácter monista o teísta de la experiencia mística, con el término de la misma, se configure como se configure éste, y la conciencia aguda de la imposibilidad de objetivarle, de tener con él una relación como la que tiene lugar entre las realidades intramundanas; es decir, que no se da como algo frente al sujeto (= ob-jectum, ob-jeto; pro-blema, en la terminología de Gabriel Marcel) y sus capacidades de conocer, experimentar, sentir, etc., como ocurre con las cosas, sino que, más bien, se da constituyendo, rodeando, abarcando, al modo como nuestra experiencia de unos padres no es sólo la de ellos, sino también la de un ámbito indefinible de desvelos, sacrificios, cuidados, preocupaciones, generosidades y desprendimientos, alegrías y dolores; amor abarcante o rodeador (misterio, en la terminología de Marcel), son dos características permanentes de lo místico y explica el hecho de que la mayor parte de las imágenes, símbolos y metáforas de casi todos ellos hablen del Misterio en términos de profundidad, Realidad radical, raiz, fuente, origen, fundamento, firmeza, etc.

La misma etimología de la palabra latina y alemana experiencia sugiere esta condición extática que hace posible percibir a Dios como fundamento, origen y meta. En efecto, como señala Bruno Forte, experientia está compuesta de ex, que evoca ese movimiento exodal: un «salir de» (cf. 
exitus) para «ir hacia» (origen, apertura y término hacia el que se va), y de perior, que está en la raíz de peritus (= perito, el que tiene conocimiento de primera mano, "por experiencia", sin intermediarios o intérpretes) o de periculum (peligro, riesgo, prueba, imponderable, contacto directo sin previsiones ni defensas). Y, en alemán, erfahrung, de erfahren -experimentar-, que viene de Land fahren, «atravesar el país». Así, la experiencia supone uun conocimiento concreto e inmediato, que no se basa en lo "sabido de oídas", sino en el contacto personal, que compromete a la totalidad del protagonista en el plano sensible y en el intelectual, que implica un riesgo y exige una cierta audacia, estimulando a la persona a ser viva y activa, y no simplemente pasiva y receptiva, frente a lo que acontece («erleben» alemán -otro término para designar la experiencia-indica precisamente «estar vivos ante el acontecimiento»). Por eso mismo, la experiencia afecta no sólo al plano existencial de la persona, determinando o modificando su modo de ver la vida, sino también el plano «existentivo», a su misma relación concreta con el conjunto de los acontecimientos en que se sitúa» (Teología de la historia, Sígueme, Salamanca 1995, 211-212). En el caso del camino místico, la pasividad que suponen los estadios finales del mismo, la noche oscura por la que ha de pasar o padecer el sujeto implica, paradójicamente -lo místico es el reino de las paradojas-, la actividad de saber recibir, cuya ciencia es infinitamente más difícil, como sabía Blondel, que la de dar, de consentir ser literalmente "pelado como una naranja» sin oponer resistencias tales como la huida, la racionalización, la construcción de un ídolo o la indiferencia.

Muchas veces, el lenguaje de los místicos es fundamentalmente descriptivo. En algunos casos, como en san Juan de la Cruz, es de una gran finura fenomenológica. Por debajo de la capa superficial de los textos, se señala o apunta una experiencia real del espíritu. Los místicos tienen un paradigma o modelo de organización de sus «textos». En parte ese modelo se corresponde (simbólicamente) con el núcleo de sus experiencias. Estos paradigmas determinan el «aire» de los testimonios o textos: el aire teresiano o tauleriano, susiano, sanjuanista o eckhartiano, etc. Y también determina sus «paradojas» lógicas. Lo dado en la experiencia mística no se percibe como caso particular de algo más genérico. El lenguaje místico no sólo es «deictémico», es decir, señalador hacia la experiencia y no hacia el diccionario, sino catalizador de la experiencia o, al menos, capaz de poner en el camino hacia ella (= experiencia intensa de unión con Dios): una experiencia subjetiva e interior cuyo contenido no se deja expresar por medio de términos cuyo sentido sería fijado por referencia a la percepción externa.

En realidad, habría que matizar lo dicho anteriormente, en el sentido de que los textos místicos tienen naturaleza de ejemplos de lo que no se 
deja ejemplificar. Por lo tanto hay que distinguir, en rigor, su significado de su referente. Pero sabiendo que ese significado no es propiamente un «deictema» para catalizar experiencias en el lector. Podríamos decir, forzando un poco el lenguaje, que es un «deictema» no catalizador. Es claro que el místico sabe que su experiencia es don de Dios, no don de un texto, en cuanto texto, aunque empiece a veces con ocasión de un texto; por ejemplo, del Evangelio de Juan o de una carta de Pablo, etc. Esto puede cuestionar no la fenomenología del fenómeno, sino la aplicación de una fenomenología «genérica». Los místicos son singularistas, y uno de los capítulos por los que sienten que sus textos o testimonios no expresan la experiencia, es porque son necesariamente genéricos. Lo que tienen de «no inteligibles» es (entre otros motivos) lo que tienen de esfuerzo por forzar un lenguaje naturalmente generalizante a hablar de lo no general.

Estas dificultades explican, de algún modo, el carácter transgresivo del lenguaje místico; es decir, «la tendencia a llevar el sentido primero de los vocablos hasta el límite de su capacidad significativa y en la utilización simbólica de todos ellos» (J. MARTín VELASCO, El fenómeno místico, Trotta, Madrid 1999, 53); su recurso constante a las paradojas y al estilo hiperbólico y exagerado, como una manera de «romper el nivel del pensamiento en el que se produce la antinomía para despertar a la nueva forma de conocimiento que corresponde a una realidad inefable en el nivel conceptual» (Ibid., 55); las frecuentes antítesis y la presencia del oxímoron que traducen en palabras la coincidentia oppositorum, de esa docta ignorantia que es la experiencia mística. Muchas veces, en fin, el lenguaje místico desemboca, como hacen algunas páginas de la música religiosa más sublime, en el silencio o, al menos, confinan con él. En cualquier caso, incluso cuando el místico parece distanciarse algo de la experiencia recurriendo a una especie de descripción fenomenológica, no puede evitar que se note su carácter autoimplicativo, lo que suele dar a sus textos esa peculiar potencia expresiva, cuando no coinciden en el mismo sujeto el teólogo, el artista poeta, el pensador y el místico, como es el caso, entre otros, de san Juan de la Cruz.

Todas estas huellas indirectas del lenguaje de los místicos, permiten «reconstruir» algunos de los rasgos más importantes de la experiencia mística y de la manera como esa vida religiosa apunta o simboliza a la Realidad de la religión (el Misterio). De ahí que los estudios sobre el tema destaquen, además de su carácter totalizador u holístico y englobante -rodeador y abarcador, dijimos más arriba-, su «inmediatez» mediada, su carácter fruitivo y de plenitud; la cierta pasividad activa que lo acompaña; la oscuridad, inefabilidad y a la vez certeza de la que parece gozar el místico; la simplicidad o sencillez que parece acompañar a los estadios 
más elevados de la experiencia mística (pobreza de espíritu, decía san Juan de la Cruz), etc., y que no son sino otros tantos ecos o reflejos de una experiencia más originaria de la que surgen, de un núcleo esencial e irreductible que supone toda una ampliación inmensa de la antropología y que está hecho de contemplación, éxtasis y unión (o unidad, cuando se trata de místicas monistas), como experiencias básicas de dicho fenómeno.

El misticismo no es algo añadido o al margen de la religión, sino la vivencia de ésta en la mayor plenitud y lucidez en todos los órdenes de la que se es capaz o, mejor dicho, de la capacidad de que dota el Misterio cuando el sujeto consiente a dejarse encontrar y agraciar por Él. De ahí que la vida de los místicos de todas las tradiciones religiosas sea un éxodo permanente de sí mismos, un transcendimiento absoluto, un éxtasis no siempre fruitivo, pues esa «inversión intencional» (Martín Velasco) que produce, supone un sufrimiento, una muerte, una noche, una conversión; un perderse en el abismo insondable del Misterio para encontrase y ganarse en un estadio que los estudiosos del fenómeno místico denominan teopático. En las místicas teístas de la bhakti hindú, o en las formas de mística cristiana, esto no es sino la otra cara del amor con que Dios ama al sujeto y éste se vive, en un anhelo incurable, como término de ese amor y «flecha» cuya inercia es ese mismo amor hacia el que vuela.

La atención a la forma de configuración del término de la experiencia mística, al modelo de relación que comporta con el sujeto (místico) -si se trata de unidad, fusión o unión- y a la «antropología» que supone; es decir, a la manera de concebirse éste a sí mismo, al estadio en el que se encuentra y del que parte hacia el encuentro con el Misterio, así como a las etapas o «escalones» del Mystical path, hará posible una fenomenología y una tipología de los distintos tipos de mística, permitiendo incorporar a ella las formas de mística no religiosas y, al mismo tiempo, haciendo ver la diferencia fenomenológica con respecto a las formas religiosas de la misma; pero no seguiremos aquí ese camino, sino más bien -de la mano de san Juan de la Cruz-, presentaremos el camino místico que propone destacando la condición transformadora e iniciática del mismo.

En efecto, también la experiencia mística consiste en un morir y en un nacer a una nueva condición. Si se atiende al que parece ser el sujeto de la relación, le encontramos en un estado preliminar (A), de partida, como señala 2 Subida 2 , y de forma menos dinámica y más diacrónica 1 Subida 2, que exige una "negación inicial» (Baruzi), un recogimiento, pues el término de donde el sujeto parte es de una estructura de atadura en esta fase de tiempo T1, que debe ser liberada. Este status inicial 
(A) desemboca en la primera experiencia de la Noche, el gran símbolo total de Juan de la Cruz. Comienza el tránsito, el margen o la transición: «Se llama noche este tránsito que hace el alma a la unión con Dios» (1 Subida, 2, 1). Cuando alguien está en un estado de umbral, separado de su condición anterior y aún no incorporado a una nueva (= unión con Dios), constituye una amenaza para sí mismo; la identidad peligra y se pierde pie, el miedo puede detener a muchas almas a entrar en esta purificadora y radical experiencia: «Las cuales comenzando el camino de la virtud, y queriéndolos nuestro Señor poner en esta noche oscura para que por ella pasen a la divina unión, ellos no pasan adelante; a veces por no querer entrar o dejarse entrar en ella, a veces por no se entender y faltarles guías idóneas y despiertas que los guíen hasta la cumbre» (Subida, prólogo, 3). Este tránsito o Noche pasiva de la contemplación estará jalonado por umbrales de paso por los que la purificación se hace más radical: todo el sujeto (entendimiento, memoria y voluntad) debe despojarse en pobreza espiritual, en fe absoluta para atravesar ese tránsito, vivido al principio como un impulso del deseo (élan místico) -como muestran las estrofas 1-12 de Cántico (A)-, pero, después, con el paso a la contemplación, como un don de la gracia. Por último, el término del movimiento -el status $B$, en la fase de tiempo T2-, la unión con Dios en el amor como estado teopático final, jalonado por una noche más terrible aún: la noche del espíritu, la aurora de la revelación de Dios en el amor.

Volviendo al punto de partida. El sujeto se encuentra fijado por lo que Juan de la Cruz denomina apetitos. Varios autores modernos han señalado el contexto correcto de esta expresión; no es simplemente un uso escolar el que hace de él Juan de la Cruz, sino que apunta a un fenómeno de experiencia real: la fijación, la inmovilización del dinamismo afectivo por detenimiento en una etapa infantil que compromete así la expansión y el equilibrio de la plenitud de la vida. Con la misma radicalidad que el filósofo actual Jean-Luc Marion (cf. L’idole et la distance, Grasset, Paris 1977, 23ss), Juan de la Cruz quiere impedir a toda costa que el sujeto objetive, congele y paralice ese impulso infinito hacia el absoluto y lo divinice, haciendo de él un ídolo. La mirada coaguladora de lo divino de Marion, que evita atravesar la representación y perderse en el infinito, aparece en Juan de la Cruz vivido en un nivel más radical, más total: toda la existencia humana puede curvarse sobre sí y negarse el futuro, entrando en un proceso mítico de venida a menos del tiempo.

En el estado de la Noche del sentido, el sujeto parece vivirse como $f i$ nitum non capax infiniti, y así hablan los textos, aparentemente duros, de 1 Subida 4. En este texto se habla de que la relación Dios-ser de las 
criaturas es como la que hay del ser a la nada; es decir, parece negar toda posible analogia entis en una postura muy barthiana de fe absoluta. Tanto Fernando Urbina como F. Kelly Nemeck han llamado la atención sobre el hecho de que «nada» no apunta aquí a la realidad existente de las cosas, cuanto al «apetito» o «fijación» que ata posesivamente a la realidad. Lo que lleva a la nada es precisamente la atadura, la detención de un ser -el hombre, hecho para lo infinito-, en una realidad finita-idolizada. Para quebrar esta estructura de atadura el sujeto debe crear unas disposiciones previas: unificación, concentración, estar presente a sí mismo; es decir, tiene que haber un verdadero sujeto. Este es el objetivo de los caminos ascéticos de todas las religiones, de todas las vías iniciáticas, hacer llegar al sujeto religioso a una madurez tal, a una tal provocación, a una estatura tal, que le irrumpa y se le de -de forma gratuita e inmanipulada- el término de la relación religiosa.

Con todo, el sujeto no está completamente abandonado de Dios e incapacitado para ir a Él. Es Él mismo quien, en los textos de Juan de la Cruz, parece meter al alma en ese tránsito (= ser el agente del tránsito): "Sin otra luz y guía / sino la que en el corazón ardía», pues «el amor solo que en este tiempo arde, solicitando el corazón por el Amado, es el que guía y mueve al alma entonces, y la hace volar a su Dios por el camino de la soledad, sin ella saber cómo ni de qué manera» (2 Noche, 25, 3). En la primera canción del Cántico B, comentando el verso «Amado, y me dejaste con gemido», dice Juan de la Cruz: «Este gemido, pues tiene aquí el alma dentro de sí en el corazón enamorado, porque donde hiere el amor allí está el gemido de la herida clamando siempre en el sentimiento de la ausencia» (Cántico [B], 1-14). Que el sujeto esté herido es tanto como decir que está abierto. Este descubrimiento se hace experiencia en la Noche y se convierte en impulso para seguir adelante hasta donde pueda, pues llega un momento en que debe ser liberado por otro, entrar en una hondura mayor, en una pasividad. Esta fase ascética que es a la vez activa y pasiva (cf. 1 Subida, 13, 1), ha puesto al sujeto ante su abismo, le ha llevado a su "más profundo centro», a su abismo más hondo, al toque sustancial, al corazón (cf. 2 Noche, 2, 17, 2: «Dentro del alma sustancialmente»).

Es precisamente este «centro del alma»-Grund, fondo, raíz, apex animae, chispa, Grund-Abgrund (fondo sin fondo) de los místicos del norte- quien es capax Dei. De la actitud de posesión se pasa en esta iniciación a la pobreza de espíritu (cf. 2 Subida, 7; 24, 8), a la irrupción y experiencia de ser referido al término, en tender al cual consiste como sujeto. Este «profundo centro» sólo se pone en marcha cuando irrumpe el término de la relación, que en todo momento no pierde su calidad de Mis- 
terio, de totalmente otro, indisponible, verdadero sujeto y centro de una relación originaria y originante, sólo accesible por un acto de absoluto trascendimiento: «Entréme donde no supe / y quedéme no sabiendo / toda sciencia trascendiendo» (Poema 9, 1. a estrofa). Una realidad íntimamente presente que supera toda dualidad de lo que es relativo permitiendo la unidad sin confusión de la participación, como muestra la constante fómula de Juan de la Cruz: "Cuan se puede en esta vida». Trascendencia que en Juan de la Cruz designa el carácter propio de Dios expresado en la kénosis del Hijo como palabra única y última para el hombre, como muestra el gran texto cristológico de 2 Subida 22, 5. Juan de la Cruz ve en este momento al hombre como "Dios por participación», cuyo centro es Dios mismo: «El centro del alma es Dios, al cual cuando ella hubiere llegado según toda la capacidad de su ser y según la fuerza de su operación e inclinación habrá llegado al último y más profundo centro en Dios» (Llama, canción 1. a , 12).

¿Qué ocurre, además, en este tránsito con la relación misma? También sufre una radical transformación y conversión. Al superar por medio de las Noches las ataduras a los apetitos, supera la forma de relación que rige para con los objetos del mundo. La experiencia de la iluminación contemplativa libera la profundidad de la razón que se abre a su fundamento, acogiendo, convirtiéndola en deseo radical que la saca de sí. Expresiones como "noticia general amorosa» nos ponen en la pista de esa nueva mirada inobjetiva acaecida por la iluminación; el que estaba herido «del alma en el más profundo centro» descubre que es una «atractura», amor de Dios puesto en pie; que su fondo último, lo realmente real de su ser -su esencia-, es ese ser-de-referencia al fundamento al que está abierto. Es el impulso del amor el que hace que en este momento nazca un «milagro»: el aparente finitum non capax infiniti, se convierte ahora en capaz de Dios. El místico ve la analogía entis porque vive desde más abajo de ella, le parece tan sólo como la corteza cognoscitiva de una experiencia mucho más honda de carácter anagógico.

Para comprender mejor esta escisión íntima o herida ontológica en que consiste la presencia inobjetiva del Misterio en el hombre -y que hace posible el paso por la noche-, de su carácter constituyente y provocador de todo tipo de expresiones, habría que analizar con mucho mayor detenimiento la paradójica constitución corporal del hombre: la experiencia de la desproporción entre lo que somos y lo que tendemos a ser; 0 , como decía Blondel, el hecho de que «de mí a mí mismo hay un abismo que nada puede colmar» (La Acción, BAC, Madrid 1996, 386), se despierta o hace posible porque somos un "cuerpo subjetivo» (categoría que Michel Henry, por ejemplo, toma de Maine de Biran) que nos abre al 
mundo precisamente porque está inhabitado de interioridad, porque hace de nosotros el habitáculo en el que estamos y somos vivientes («alma», en la terminología de Henry), permitiendo que seamos una «caja de resonancia» de ese más allá de nosotros mismos que nos constituye y que habla, precisamente, haciéndonos hablar (J. L. Chrétiene), provocándonos, como el motor de nuestra vida espiritual, a poner nombre a esa «visita originaria», imposible de explicar porque está en la base de toda comprensión como aquello, precisamente, que la hace posible. Una «caja de resonancia» que, permitiendo esa «extraña acústica del mundo espiritual» (M. Henry), y todo tipo de conexiones y reverberaciones, ilumina la realidad creada permitiendo verla, gracias a esa anagogía, como el reflejo de la Belleza, la Verdad y el Ser que tienen en Dios su fundamento. El hombre es un ser capax symbolorum porque él mismo es un símbolo originario, porque hay una interesante relación entre interior y exterior, entre interioridad y exterioridad en su misma constitución. Nunca termina de ver reflejado del todo en el «espacio exterior» la previa presencia originaria y donante del Misterio que provoca a que, desde su «espacio interior», resuene y cobre voz al reflejarse en las realidades intramundanas. La experiencia del paso por la noche hace posible la decostrucción del sujeto a partir de la irrupción de la exterioridad, del o(O)tro, así como el «acceso» a la profundidad patética del propio ser, escrutando las zonas más recónditas del mismo para descubrir la presencia inobjetiva del Misterio que se manifiesta, sin dejar de ser tal, en la esfera más íntima de la subjetividad.

Según Michel Henry, la esencia de la manifestación es la afección, la vida que se nos revela antes que todo en nuestra propia vida, y ante la cual no nos encontramos como frente a un objeto; del mismo modo que la luz, que hace posible lo iluminado pero que ella misma no se ve, así «nadie ha visto nunca la vida ni la verá jamás. ¿Quién ha visto la propia pena, la propia angustia, el propio amor? ¿Quién ha visto jamás a Dios?», se pregunta Henry en el prefacio que escribió para la traducción italiana de su Genealogía del psicoanálisis $(1985 ; 1990)$. Por lo que respecta a Dios, no sabemos nada sino en la medida en que Él se revela. En el intento de preguntarse cómo se manifiesta Dios a nosotros, coinciden la búsqueda fundamental de la fenomenología con la indagación propia de la teología, puesto que de lo que se trata no es tanto de establecer qué cosa se dona, se revela o manifiesta, sino el cómo se dona o revela (Dios, en el caso de la teología; las cosas o la vida, en el de la fenomenología). Evitar que la luz de lo que se muestra no ciegue para detectar el aparecer mismo (que Henry llama «fenomenicidad») de lo que aparece. Es lo que expresa en textos tan difíciles como este: 
«Revelación sólo hay y sólo puede haber cuando el modo de donación extático en el afuera de un mundo, deja paso a un modo de fenomenización de la fenomenicidad tan radicalmente diferente, que no es un destello de luz del primero que penetrara en la materia fenomenológica del segundo, sino que de este modo, al ser heterogéneo al primer modo de aparecer, el segundo se da como una revelación» («Qu'est-ce qu'une révélation», Archivio di Filosofia 1-3 [1994] 52).

Para que haya revelación, se necesita que se dé una ruptura radical entre la aparición inicial y lo que se desvela en último término. Ruptura que afecta al cómo de la donación misma y no tanto al modo en que se manifiesta. No pensemos que términos como «esencia» o «fenomenicidad» apuntan hacia algo abstracto o general; antes bien, señalan la plenitud individual y la máxima concreción. Como si en el núcleo íntimo de lo que se muestra hubiera ya algo que se resiste a ser objetivado y que escapa del saber de la representación.

Pero la vida humana es autoafección, auto-sentir y auto-padecer, afectividad, soledad cuyo contenido es la Parusía como esencia de la vida. Por tanto el Absoluto, además de trascendencia suma, es también pasividad, radical inmanencia. La vida es sufrimiento y alegría nunca separados. El primero es como la carne de la que la Alegría está hecha y mediante este sentimiento tornasolado, la subjetividad que somos aparece como «autoafección del Absoluto» que nos hace seres vivos con el sentimiento de sí mismos; donde la afectividad, como esta experiencia inmediata de sí y como experiencia no teórica o especulativa, aparece como lo más concreto del «sentirse a sí mismo»: pasividad ontológica originaria, amor espiritual. Hasta el punto de que el cristianismo viene a sustituir la pura formalidad de la ley kantiana por la ley del amor: «Con la sustitución del amor por el respeto, y precisamente gracias a ella, Kant se ha creído en sintonía con el cristianismo, pero éste reposa justamente sobre la sustitución inversa, sobre la de la ley por el amor, y es por ello que su pensamiento supremo es el no-pensamiento, la unidad con la vida absoluta, [...] con Dios mismo» (L'essence de la manifestatiom, PUF, Paris [1969] 1990, 666).

Esta experiencia estalla en la obra diurna: Cántico y Llama. Juan de la Cruz descubre ahora la realidad transfigurada; ve el lado por el que las cosas y las personas están cargadas de infinitud: aquél por el que creadas por y para Cristo -y en él consistentes (Col 1, 15-20)- remiten al Padre. Llama canta el hecho y la fe de verse inmerso en ese movimiento circular de la Trinidad en la historia. Nada es remitido al Padre sino por o en el Espíritu Santo, verdadero protagonista de Llama. El Padre le ama 
en y con el amor que engendra al Hijo (históricamente encarnado, muerto en la cruz y resucitado -cf. el texto cristológico-); y él ama al Padre en y con el amor con que el Hijo lo ama y lo conoce, y procede del Padre, y utiliza su amor para ejercer su amor al Padre, y ese amor es Dios Espíritu Santo. Y esto lo vive el místico no como un sentido de cosas, sino como un acontecimiento real -sucediente-, como sentimiento real de presencia de Dios real. Vive el misterio trinitario del amor de Dios como su patria real, si bien el Cristo joánico fue más atrevido: nosotros somos la patria de la Trinidad -«vendremos a él y haremos morada en él» (Jn 14, 23. Cf. Llama, 1, 15)-. Y así, en el status B (tiempo T2), Juan de la Cruz contempla el misterio último de la realidad como un océano de amor que pone todo en razón: «[...] En lo cual parece al alma que todo el universo es un mar de amor en que ella está engolfada, no echando de ver término ni fin donde se acabe ese amor, sintiendo en sí, como habemos dicho, el vivo punto y centro del amor» (Llama, 2, 10). Estado teopático, o misterio de la unión con Dios que conjuga la dialéctica del acto religioso cristiano -la unión y la diferencia-, en una transformación que es participación en la vida de Dios y, por ello, hominización total. Al tener Juan de la Cruz una representación fuertemente personalizada del Misterio, no porque a éste se le atribuyan las notas de la persona, sino porque es el fundamento de nuestro ser personal, expresará la unión en términos de adecuación de voluntades entre Dios y el hombre (cf. 1 Subida, 11).

Como ya se ha insinuado en otra ocasión más arriba, la experiencia mística tiene lugar en el interior de la fe de cada tradición religiosa como una vivencia plena y lúcida de ésta. El místico hace la experiencia de que todo es más de lo que es: las cosas todas, la naturaleza, nuestro mundo, las personas, el sujeto mismo. Vive todo como dotado de un lado interior, invisible, profundo; como cargado de infinitud. Cuando se trata de un místico cristiano, esa infinitud es consecuencia del hecho y la fe de que todo ha sido creado en por y para Cristo, remitiendo al Padre por o en el Espíritu Santo. Todo remitiendo, apuntando, señalando hasta el padecimiento y la sed de que nada «sabe decirme lo que quiero», pero que no termina en la desesperación, a pesar de las más oscuras noches, porque siempre dura más tiempo que las ausencias y desamparos la tenue y silente voz de ese hacia o para final y de origen que el místico percibe tan instalado en las cosas y las personas, de modo que se vive todo él como anhelo, «tensión hacia» (epextasis, decía Gregorio de Nisa, el más platónico de los padres), capacidad de recepción de la presencia constituyente de Dios, paradójica sed e insuficiencia que, por gracia, plenifica. «Estas cavernas - dice san Juan de la Cruz- son potencias del alma [...] las cuales son tan profundas cuanto de grandes bienes son capaces, pues no se 
llenan con menos que infinito» (Llama de amor viva, 3, 18, 22), magnífica expresión del finitum capax infiniti.

De ahí el talante lírico de muchos místicos, puesto que podríamos decir, sin temor a exagerar, que lo místico es lo lírico de la experiencia religiosa, por su afán de intimidad y confidencia, por la potenciación y glorificación de todo lo concreto al vivirlo desde su dimensión de profundidad, gracias a la «inversión intencional», y a la potenciación, también, del registro afectivo de sentimientos y emociones que no dejará de tener un eco en el mismo lenguaje. Lo místico es como el «por de dentro» (Quevedo) de la experiencia religiosa que, sin embargo, no puede dejar de irrumpir, de llegar a expresión, siendo a su vez, la condición de posibilidad de la lucidez en todos los órdenes: especulativo, ético, estético, religioso. En su experiencia del precipitarse de todo hacia Dios, los místicos padecen la hermosura de las cosas porque las ven caducas, al ser hoy y no ser mañana; al pasar y, sin embargo, estar dotadas de esplendor, las viven a la vez como siempre nuevas aunque no duren casi nada. De ahí que muchos de ellos, dotados de genio artístico, hayan intentado eternizar el instante de lo que es hermoso por efímero. Al afinar la sensibilidad lírica, la experiencia mística hace posibles y convoca las experiencias éticas, teóricas o de amor al prójimo sin sentirlo como un añadido contrapuesto a su núcleo esencial, sino como una consecuencia obediente a su lógica interna. La verdadera «inversión total de intencionalidad» (J. MARTÍn VELASCO, o.c., 414) que supone el paso por la noche oscura, transmuta las maneras de conocer, sentir, imaginar, etc., de un uso controlador, posesivo y dispersante a otro participativo o receptivo, agápico y libre -sin ataduras, o al menos consciente de sus peligros-, unificante. Es justamente este cambio, verdadera conversión de la mirada y el corazón, ahora raíz de ella, el que dota al místico de esa vivencia tan peculiar de la fe como es la figura de la contemplación. Basta para constatarlo, leer un texto realmente increíble de San Juan de la Cruz, cuando comenta el verso "y vámonos a ver en tu hermosura»: "Que quiere decir: hagamos de manera que por medio de este ejercicio de amor ya dicho lleguemos hasta vernos en tu hermosura en la vida eterna; esto es, que de tal manera esté yo transformada en tu hermosura, que, siendo semejante en hermosura, nos veamos entrambos en tu hermosura, teniendo ya tu misma hermosura; de manera que, mirando el uno al otro, vea cada uno en el otro su hermosura, siendo la una y la del otro tu hermosura sola, absorta yo en tu hermosura; y así te veré yo a ti en tu hermosura, y tu a mi en tu hermosura, y yo me veré en ti en tu hermosura, y tú te verás en mi en tu hermosura; y así parezca yo tú en tu hermosura, y parezcas tú yo en tu hermosura, y mi hermosura sea tu hermosura y tu hermosura mi 
hermosura; y así seré yo tú en tu hermosura, y serás tú yo en tu hermosura, porque tu misma hermosura será mi hermosura; y así nos veremos el uno al otro en tu hermosura» (Cántico espiritual [B], 36, 5).

Veinticinco veces, sin contar las variaciones adverbiales o adjetivas, aparece en este texto monumental del lirismo la palabra hermosura. En él no estamos frente a una simple descripción, sino en el terreno «exagerado» de la adoración religiosa, de la oración, de la religión en acto, donde el transcendimiento del sujeto está más en «el Amado» -en el Dios filiante (cf. la cita siguiente de Jn 17, 10), término de la actitud religiosaque en el lector. En quien decían que se holgaba de que Dios tuviese tanta hermosura, no sorprende una creación semejante que, por otra parte, no es un texto aislado en su obra (cf. Cántico, 5, 4; 6, 1; 11, entre otros).

Con todo, el místico auténtico es una persona lúcida, que no se engaña. Basta para ello leer con detenimiento los primeros capítulos de la Noche oscura de san Juan de la Cruz, para darse cuenta de la finura con que el santo pone el dedo en la llaga de los peligros que acechan a quien se adentra en la búsqueda de la unión con Dios y ha pasado ya los primeros estadios en los que los avances parecen espectaculares; es decir, de las ilusiones y engaños que pueden ocultarse sub angelo lucis. La aguda conciencia de un fenómeno típico de la vida religiosa, y por tanto también de la intensidad de la experiencia mística, de que sucede como si, a la par y en uno, estuvieran juntas la religión y lo que en ella la contradice (la falta de religiosidad). Si existir religiosamente es reconocer personalmente al Tú Eterno, dándole espacio en la propia vida y haciéndole sitio en el mundo, eso supone ya la entrega de uno mismo a un proceso o dinamismo de transcendimiento que no nos deja igual para el resto de la vida. Por eso, la tentación de la falta de religiosidad, como consecuencia de experimentar en vivo la gran distancia, el abismo que hay de mí a mí mismo (y que yo no puedo colmar, como gustaba de decir Blondel) entre mi testimonio y la intención que lo inhabita y provoca, puede tomar las más diversas formas; entre otras: la constante caída en el desamor y en el egoísmo; el ceder al "entristamiento» o al sin sentido; la participación irreflexiva en los actos litúrgicos; el refugio en un falso «misticismo», creyendo poder estar casi de continuo en el ámbito de lo sagrado disponiendo de él a nuestro antojo; el engañarse sobre Dios con teorías insignificantes, haciendo absolutos de nuestras «teologías» y rechazando todo lo que no entra por los estrechos moldes de ellas y aceptando, sólo, lo que subraya o confirma nuestras opiniones, etc, etc. El místico no ve otra solución a todo esto que pedir denodadamente a Dios la virtud de la humildad y el arrojo de no ceder al abandono de la tensión del espíritu. En esos momentos, toma conciencia de que su vida religiosa es muchas ve- 
ces, al menos, una trivial y muy frecuentemente aburrida conversación por su parte con un interlocutor de una calidad excelsa.

Esa humildad le pone al místico en camino de reconocer que está siempre en el inicio de la comprensión y que, en cuestiones de religión vivida, puede darle lecciones cualquiera (como en casi todo). El camino de ese transcendimiento es largo y semejante desapego costoso. Los éxitos en el mismo, el hecho de que a veces esté inspirado y que, dentro de él, la presencia inobjetiva de Dios le dote de capacidad, de resonancia que hace de toda criatura "palabra y símbolo» (como decía Nietzche, refiriéndose a la inspiración poética, con un lenguaje de asombrosa correspondencia homeomórfica con la revelación religiosa); que le remita, apunte y hable -como se dijo más arriba-, convirtiéndose en "palabra», no le ciega de tal modo que no vea la posibilidad, siempre actual, de comenzar a precipitarse por el plano inclinado del gozo de su «sí-mismo» deteniendo, en ese mismo instante, la actitud extática de reconocimiento y adoración de la alteridad suma de Dios que, por ser tal, puede al mismo tiempo ser la presencia más íntima a nosotros que quepa imaginar (interior intimo meo). 